\title{
O ESTADO DO PARANÁ: DA ESTRATÉGIA DE INTEGRAÇÃO ESTADUAL AOS CORREDORES BIOCEÂNICOS
}

\section{PARANA STATE: FROM THE INTEGRATION STRATEGY TO THE TRANSOCEANIC CORRIDORS}

\author{
Cinthia Abrahão ${ }^{1}$ \\ Sony Cortese Caneparo ${ }^{2}$ \\ Ricardo Sena Abrahão ${ }^{3}$
}

\section{RESUMO}

$\mathrm{O}$ artigo aborda a questão do investimento na infraestrutura viária como elemento da integração territorial do estado do Paraná, por conseguinte, aspecto central na estratégia de desenvolvimento econômico. Nas décadas que sucederam o período pós-guerra, especialmente entre os anos 1950 e 1970, fica clara a necessidade de afirmação do estado dentro do cenário nacional. Para tanto, a consolidação da rede viária exerceu papel fundamental como unificadora e viabilizadora do escoamento da produção exportável do estado através do porto de Paranaguá. A partir da crise econômica dos anos 1980 e de forma mais aprofundada na década de 1990, emergiu um novo perfil de gestão do território e de fomento do eixo de circulação consolidado no estado. A última década dos anos 2000 trouxe aportes no que se refere à unificação territorial, projetando o fortalecimento do eixo territorial originalmente definido como tronco do desenvolvimento econômico do estado do Paraná. A abordagem aqui proposta busca destacar a relação dessa estratégia com o fortalecimento do vértice formado por Curitiba (capital) - Paranaguá (porto) em sua trajetória histórica e em sua conformação atual.

Palavras-chave: Paraná; IIRSA; PAC; Porto de Paranaguá.

\section{ABSTRACT}

The paper boards the issue of investment in road infrastructure as part of the territorial integration of the state of Parana, therefore, a central feature in the economic development strategy. In the decades that followed the postwar period, especially between 1950 and 1970, it was necessary to affirm the state into the national scene. To this end, the consolidation of the road network served as a unifying role and enabler of the flow of exportable production of the state through the Paranagua port. From the economic

1 Graduada em Economia pela Universidade Federal do Uberlândia (UFU), Mestre em História Econômica pela Universidade de São Paulo (USP), Doutora em Geografia pela Universidade Federal do Paraná (UFPR). Atua desde 2005 como docente na UFPR Setor Litoral. E-mail: cinthiaabrahao@ufpr.br

2 Graduada em Geografia pela Universidade Federal do Paraná (UFPR), Mestre em Ciências Geodésicas pela Universidade Federal do Paraná (UFPR), Doutora em Meio Ambiente e Desenvolvimento pela Universidade Federal do Paraná (UFPR). É professora adjunta do departamento de Geografia e do programa de pósgraduação em Geografia da UFPR.

3 Graduado em Engenharia pela Universidade Federal de Uberlândia (UFU), Especialista em Gestão Estratégica e Logística pela UFU. Atua como docente na área de projetos e logística da UNIESSA.

Divers@ Revista Eletrônica Interdisciplinar/Matinhos/Vol.5,n.1/p.1-92|/jan./jun.2012 
crisis of the 1980s, and in more depth in the 1990s, there emerged a new profile of land management and promotion of the axis of movement in consolidated state. The last decade of the 2000s brought intakes in relation to the territorial unification, designing the strengthening of the territorial axis originally set to stem the economic development of the state of Parana. Our approach aims to emphasize the relationship of this strategy with the strengthening of the triangle formed by Curitiba (capital) - Paranagua (port) in its historical trajectory and in its present conformation.

Keywords: Paraná; IIRSA; PAC; Paranaguá Port.

\section{Introdução}

$\mathrm{O}$ artigo aborda a questão do investimento na infraestrutura viária como elemento da integração territorial do estado do Paraná, aspecto central na estratégia de desenvolvimento e na definição do seu papel no contexto da divisão nacional do trabalho. Nas décadas que sucederam o período pós-guerra, especialmente entre os anos 1950 e 1970, ficou clara a necessidade de afirmação do estado dentro do cenário nacional, o que implicou no reforço do vínculo econômico e territorial da capital, Curitiba, com as demais porções territoriais que administrativamente compõem o estado. A consolidação da rede viária exerceu papel fundamental como unificadora e viabilizadora do escoamento da produção exportável do estado através do porto de Paranaguá.

A partir da crise econômica dos anos 1980 e, de forma mais aprofundada na década de 1990, emergiu um novo perfil de gestão do território e de fomento do eixo de circulação consolidado no estado. Da mesma forma a ideologia neoliberal assumiu uma conotação específica no âmbito estadual, de tal maneira que a estratégia da unificação/centralização territorial continuou visível. O que assumiu novos formatos tendo em vista o movimento de redução da intervenção direta do Estado na economia e, sobretudo, a desmobilização de sua capacidade planejadora.

A última década dos anos 2000 trouxe novos elementos para a questão da unificação territorial, que envolvem a estratégia sul-sul e a retomada do investimento federal na infraestrutura. Em termos de elementos concretos que apontem nesse sentido merecem destaque a articulação da Iniciativa para Integração da Infra-estrutura Regional Sulamericana (IIRSA) e a concepção e implantação do Programa de Aceleração do Crescimento (PAC). Em ambos os casos, os investimentos, naquilo que afetou diretamente a região, projetou o

Divers@ Revista Eletrônica Interdisciplinar/Matinhos/Vol.5, n.1/p.1-92|/jan./jun.2012 
fortalecimento do eixo territorial originalmente definido como tronco do desenvolvimento econômico do estado do Paraná. A abordagem aqui proposta busca destacar a relação dessa estratégia com o fortalecimento do vértice formado por Curitiba (capital) - Paranaguá (porto) em sua trajetória histórica e em sua conformação atual.

Tendo em vista organizar esses argumentos, o artigo foi dividido em duas partes. $\mathrm{Na}$ primeira buscamos discutir os fundamentos da integração territorial e do desenvolvimento econômico no Paraná do pós-guerra. Na segunda parte buscamos destacar os caminhos propostos na década de 2000, bem como os movimentos de mudanças e permanências.

\section{Integração Territorial e Desenvolvimento econômico: o pós-guerra no estado do Paraná}

Os anos 1950 foram férteis na discussão acerca da necessidade de autonomia do estado do Paraná em relação a São Paulo. Segundo IPARDES (1979, p.10), "São Paulo como centro industrial [...] tinha no Paraná a sua maior demanda, inclusive por serviços". A porção norte do estado, no entanto, chegou mesmo a receber o suporte de infraestrutura de transportes por parte do estado de São Paulo. Assim, foi paulatinamente reforçada a ideia de que a autonomização deveria envolver a retomada das rédeas sobre as regiões desgarradas do estado.

A concepção do plano rodoviário de 1951 deixava clara a busca de independência econômica, cuja condição passava pelo domínio territorial. Nas palavras de Luiz Carlos Pereira Tourinho, engenheiro responsável pelo plano rodoviário do governo Bento Munhoz:

[...] elaborei este plano rodoviário que tinha como ideia fundamental vencer a resistência do Porto de Santos. Até então só se falava que toda a produção paranaense devia sair (por) Santos. [...] Esbocei um plano com a palma da mão sobre Curitiba e com sete grandes troncos dirigindo o Estado do Paraná, quase todos eles montados sobre grandes divisores de d’água (Luiz Carlos Tourinho, 1996, IN: ROCANGLIO, 1996, p.55).

A consequência da implementação da estratégia de integração foi possibilitar que o porto de Paranaguá assumisse o papel de responsável pelo escoamento da produção de café do Paraná. A construção da Estrada do Cerne (atual PR090) foi um primeiro passo no sentido de possibilitar o escoamento da produção através do Porto de Paranaguá, voltando a dar centralidade ao eixo comandado por Curitiba-Paranaguá. Toda a estrutura de circulação paranaense, que começou a ser construída em consonância com a perspectiva da integração nacional, teve em Curitiba um centro político, que se converteu progressivamente em eixo

Divers@ Revista Eletrônica Interdisciplinar/Matinhos/ Vol.5, n.1/p.1-92|/jan./jun.2012 
econômico. Isto ocorreu à medida que os fluxos de mercadorias passaram a encontrar nessa cidade a maior dotação de equipamentos para viabilizar sua circulação. A consequência lógica do processo foi estabelecer uma nova hierarquia nas relações socioeconômicas e políticas. Seguindo tal proposição, destacamos que no Paraná a premissa de que poder e desenvolvimento caminham de braços dados foi levada a sério, especialmente na segunda metade do século XX. De tal forma que fortalecer Curitiba significou, do ponto de vista do escoamento produtivo, fortalecer o Porto de Paranaguá e vice-versa.

Consideramos que a análise da estruturação da rede pavimentada de rodovias no estado do Paraná representa uma chave para compreensão do processo de fortalecimento da economia regional. Conforme IPARDES (1979, p. 27), a inteligência planejadora do Estado assumia como dado que

[.... a estrutura produtiva do Paraná [era] basicamente voltada para a produção agrícola e agroindustrial, seja para exportação, seja para o mercado interno, não resta dúvidas que a melhoria das ligações viárias com a capital e desta com o Porto de Paranaguá, bem como o aparelhamento deste, propiciaram a consolidação de uma economia interna.

A implantação do sistema rodoviário no Paraná, por sua vez, foi consonante com o momento em que este se desenvolveu em nível nacional. Tal consonância e prioridade para o modal rodoviário terminou por conduzir à marginalidade do sistema de transporte as demais modalidades de transporte (IPARDES, 1979, p. 5-8). As insuficiências da malha ferroviária, tanto em termos de condições técnicas, como de traçado ficaram evidenciadas. Destacava-se a baixa flexibilidade do modal ferroviário mediante o princípio norteador de sua montagem, que era o atendimento do escoamento agroexportador.

Entre as décadas de 1950 a 1970 observa-se um esforço considerável no sentido de garantir ao estado do Paraná infraestrutura de transporte moderna e ágil. O que possibilitou ao estado encontrar uma posição dentro do novo quadro econômico do Brasil pós-guerra, criando as bases da modernização de sua agricultura exportadora a partir do modelo da Revolução Verde. Tal modernização gerou uma cadeia de valores cujo escoamento através de seu sistema portuário aparece como um primeiro grande resultado das estratégias de unificação e desenvolvimento ${ }^{4}$.

Existe uma relação íntima entre conteúdo e forma de domínio político, que se expressam na materialidade institucional do Estado capitalista, seu complexo de instituições e

4 Abordamos aqui conceito de desenvolvimento na perspectiva contextualizada, isto é, tal como foi compreendido ao longo do Processo de Substituição de Importações, em especial durante o regime militar.

Divers@ Revista Eletrônica Interdisciplinar/Matinhos/Vol.5, n.1/p.1-92|/jan./jun.2012 
normas que balizam sua atuação. No Estado do Paraná, em função de sua transição tardia e dependente dentro do quadro do capitalismo nacional, altamente vinculado às dinâmicas econômicas movidas pela economia paulista, observa-se que a conjuntura do pós-guerra criou condições excepcionais de reposicionamento na divisão nacional do trabalho. Consoante com o processo sociopolítico ocorreu a organização de um corpo burocrático, centralizado na capital, e capaz de articular oportunamente as diretrizes do governo federal e convertê-las em meios para completar um processo de transição. Tal processo, por sua vez, teve foco no fortalecimento do estado e na inserção de Curitiba no conjunto de cidades influentes política e economicamente no cenário nacional.

A política de transporte exerceu papel estratégico nessa conjuntura, para a qual tornouse vital o fortalecimento das instituições, em especial da Secretaria Estadual de Transportes do Estado do Paraná (SETR-PR). Ligados à Secretaria estão o Departamento de Estradas e Rodagem (DER), a Administração dos Portos de Antonina e Paranaguá (APPA) e a Estrada de Ferro Paraná Oeste S.A. (Ferroeste). Através dessa estrutura a SETR, desde sua criação em 1969, tornou-se a instituição congregadora da missão de integração do estado. No entanto, a desmobilização das fontes de financiamento das ações de transformação territorial exigiu novas soluções que viabilizassem a conclusão do projeto do Paraná moderno, desenvolvido e, por conseguinte definitivamente integrado.

Devemos destacar a natureza crítico-dialética do processo de acumulação de capital inerente ao sistema capitalista. Conforme Harvey $(2005$, p.151) as alianças de classe que sustentam as estruturas de poder, que se vinculam mais ou menos a um território, são portadoras da ruptura do equilíbrio e da coerência, revelando que "as alianças se destinam a ser instáveis". Nessa perspectiva, o que se observa é que em âmbito nacional houve um esgotamento do projeto político de consolidação do capitalismo industrial autárquico, bem como do projeto de liberalização controlada iniciada dentro do regime autoritário em 1973 (SALLUM JUNIOR, 1995, p. 141).

Mencione-se que foi sob a ótica do Estado desenvolvimentista-nacional que o projeto de integração territorial e desenvolvimento econômico foi implementado até os anos 1980 no estado do Paraná. Conforme Lima e Dias (2008), ao longo dos anos 1970 quase metade da renda do Estado foi investida na infraestrutura de transporte, incluindo os projetos de ampliação, melhorias de pavimentação, duplicação e ampliação das rodovias BR-277 e BR376, estratégicas no que tange ao propósito de integração territorial.

Divers@ Revista Eletrônica Interdisciplinar/Matinhos/Vol.5,n.1/p.1-92|/jan./jun.2012 
O período foi bastante significativo em função da diversificação da economia paranaense. De um lado, ocorreu a decadência do setor cafeeiro após a grande geada de 1975, de outro, ocorreu a primeira etapa da instalação de um parque industrial moderno concentrado na região metropolitana de Curitiba $^{5}$. A crise agrícola paranaense, por sua vez, sofreu os revezes da política de fomento da expansão da cultura de grãos e da adoção das novas tecnologias de produção que possibilitaram uma recuperação relativamente rápida do setor. Esse conjunto de elementos e seus rebatimentos no início dos anos 1980 permitem que Lima e Dias (2008, p. 20) falem de um efeito retardatário da crise do Estado desenvolvimentista no Paraná. Ainda para os mesmos autores, o desenvolvimentismo no Paraná se estendeu até quase meados dos anos 1990, quando sucumbiu aos efeitos da crise econômica nacional.

Todavia, a crise econômica da década de 1980 representou um marco de inversão nas ações do setor público paranaense no que se refere a conduzir o sistema de integração e desenvolvimento. A extinção da fonte segura de financiamento dos investimentos rodoviários, instituída no Fundo Rodoviário Nacional (FRN) pode ser vista como um dos sintomas de um conjunto de mudanças que assumiram proporções cada vez mais expressivas.

Em nível nacional, tal década foi marcada pelo processo de transição política brasileira, mas o contexto no qual se realizou não permitiu que se resumisse às mudanças na esfera político-institucional. Conforme Sallum Junior (1995, p. 138), "nestes anos entrou em crise a própria relação poder político/sociedade, que sustentou todos os regimes que organizaram a política brasileira desde 1930”. O que se observa na escala nacional, mas também na estadual e regional.

Nesse sentido é preciso que frisemos que o grupo político, que dirigiu o Estado na segunda metade dos anos 1990, não encontrava margem de manobra fora do discurso hegemônico predominante em nível nacional. Havia um conjunto de pressões sobre a economia nacional, advindas do sistema capitalista internacional, responsáveis pelo escasseamento dos mecanismos de financiamento externo para economias como a brasileira. Tais mecanismos praticamente deixaram de existir desde os anos 1980 até o início da década de 1990, quando foram redefinidas suas bases. Tal processo foi encadeado com as mudanças político-ideológicas da virada dos anos 1990, que reposicionaram o discurso liberalizante e

5 Originalmente a industrialização de Curitiba esteve vinculada ao setor agroexportador, apenas na década de 1990 houve a instalação de uma indústria dinâmica não fornecedora.

Divers@ Revista Eletrônica Interdisciplinar/Matinhos/Vol.5,n.1/p.1-92|/jan./jun.2012 
tornaram impositivas as reformas estruturais. Dentre as quais se tornou central a redefinição do papel do Estado e sua relação com a economia.

Em que pese a força do discurso conservador, a ideia de Estado mínimo não se instalou de fato no campo de forças que redesenharam as ações públicas no Brasil dos anos 1990. Traduzido por Pereira (1997, p.17), a tônica das diretrizes reformistas revelavam que

[...] ao invés do Estado mínimo, a centro-esquerda social-liberal propôs a reconstrução do Estado, para que este possa - em um novo ciclo - voltar a complementar e corrigir efetivamente as falhas do mercado, ainda que mantendo um perfil de intervenção mais modesto do que aquele prevalecente no ciclo anterior.

Através das diretrizes do MARE (Ministério de Administração e Reforma do Estado) foram sendo moldadas as reformas brasileiras que tinham dois veios importantes, a desestatização e a criação de um marco legal capaz de possibilitar um novo papel para o setor privado. Este segundo elemento mostrou-se crucial no que se refere ao campo dos transportes e da infraestrutura de modo geral. De acordo com Silva Neto (2005, p. 72), a Lei de Transporte Multimodal de 1997 (Lei 9.611 de 19/02/1998) foi elaborada sob o novo paradigma norteador da ação do Estado, preconizando as parcerias público-privadas como elemento central para a modernização. O que por sua vez teve impacto muito relevante tanto nos equipamentos de circulação, como na atividade portuária.

No que se refere à produção do espaço econômico estavam em curso novas forças sociais, novos processos que se moviam no sentido da consolidação material, no sentido da apropriação econômica e simbólica, portanto, daquilo que denominamos como territorialização. Para Santos (2006, p.38), “os fluxos são resultado direto ou indireto das ações e atravessam ou se instalam nos fixos, modificando a sua significação e o seu valor, ao mesmo tempo em que, também se modificam.” É exatamente o processo de reconfiguração que testemunhamos ao longo dos anos 1990 de forma mais geral na escala nacional e de forma específica em cada localidade, onde o tempo-espaço apresenta uma imbricação distinta pela especificidade.

As conjunturas macroeconômica e política que marcaram o governo paranaense de Jaime Lerner, na segunda metade dos anos 1990, contribuíram para que possamos compreender a nova forma de condução das políticas de Estado no que tange à infraestrutura. Conforme Silva Neto (2005), esse político já havia construído uma trajetória como prefeito de Curitiba que pode ser responsabilizada por projetar a cidade no cenário nacional. 
Nos anos 90, Curitiba colhia os louros de ser considerada uma das melhores cidades do mundo para se viver e uma das únicas no Brasil que se elevavam à condição de primeiro mundo. Apresentava muitas expressões que a caracterizava, tais como, capital ecológica, cidade laboratório e cidade modelo (COUTO, 2002, p. 227).

Foi sob as gestões de Lerner que a imagem de Curitiba moderna assumiu finalmente o papel de referência simbólica no imaginário nacional. A projeção imagética relacionada ao embelezamento da cidade e a construção de um ethos de superioridade étnica tornaram-se componentes de sua afirmação como pólo central da rede de cidades do estado do Paraná. Infraestrutura, dinâmica econômica e simbolismo se combinam na produção da centralidade econômico-política da capital.

Em 1994, eleito governador, Lerner executou um programa de desestatização que exercia um diálogo direto com a política privatista de Fernando Henrique Cardoso no governo federal. É de se destacar que a gestão FHC foi bastante contundente na busca do alinhamento dos Estados comprometendo-se com antecipação de recursos relacionados a leilões de privatizações de estatais para os estados que aprovassem a operação com assentimento das Assembléias Legislativas. Contudo, o avanço da visão liberal foi definitivamente impulsionado pelo conjunto de oportunidades de negócios privados capazes de beneficiar os grupos de apoio ao governo Lerner (SILVA NETO, 2005, p.76-79).

Na SETR/PR, concessão de rodovias, ferrovias e privatização dos terminais de cargas do Porto de Paranaguá se tornaram diretrizes predominantes da política do novo governo estadual. Dentre as linhas de prioridade, a ação mais relevante instituída pelo governo Lerner foi a consolidação do projeto do Anel de Integração (SILVA NETO, 2005, p.82). Esse, por sua vez, concluiu o projeto de integração da estrutura viária, com a predominância do modal rodoviário, fazendo com que o fluxo de pessoas e mercadorias do estado fosse direcionado para o eixo Curitiba-Paranaguá, sob a liderança da primeira.

O Anel de Integração constituiu, na verdade, o corolário de um conjunto de ações que vinham edificando a estrutura territorial integrada do Estado. O que nos parece a expressão da capacidade de conclusão de um projeto histórico mediante condições de crescente precariedade da capacidade do Estado de exercer o direcionamento do processo de organização do sistema produtivo. Outrossim, a faceta mais evidente do projeto Lerner foi o caráter privatista designado à infra-estrutura rodoviária, que passou a contar com 2.035,5 km de rodovias concessionadas a grupos privados.

Divers@Revista Eletrônica Interdisciplinar/Matinhos/Vol.5, n.1/p.1-92|/jan./jun.2012 
Os eixos do anel de integração paranaense interligam as regiões norte, oeste, o centro e o leste, onde estão a região metropolitana e sua extensão portuária, em Paranaguá. Exatamente por isto revelam como a infraestrutura viária do Estado tornou-se aliada do desenvolvimento, particularmente dos lugares privilegiados na estrutura. Para Marx (IN HARVEY, 2005, p.49), "os custos de circulação podem ser reduzidos pelo transporte aperfeiçoado, mais barato e mais rápido". Nesse sentido, fica evidente na configuração espacial contemporânea do estado do Paraná a capacidade de potencializar o processo de transformação do espaço econômico, quando observamos o consequente fortalecimento dos núcleos urbanos e pólos regionais.

Destacamos ainda que ao observar os pólos do anel temos o que Moura (2009) representa como a reunião de conhecimento, mobilidade e conectividade atuantes no processo de metropolização do estado do Paraná. Segundo a autora, tal reunião configura, em função de uma série de políticas ativadoras dos fluxos econômicos e demográficos, uma dinâmica urbano-regional. O que, por sua vez, está vinculada "aos estágios mais avançados da inserção do território na divisão social do trabalho" (MOURA, 2009, p.16). O processo de complexificação socioeconômica torna os

[...] arranjos concentradores de população, com relevância econômico-social e na infra-estrutura científico-tecnológica, elevada densidade urbana e forte articulação regional, e extrema complexidade, devido à multiplicidade de fluxos multidirecionais de pessoas, de mercadorias, finanças e de relações de poder que se materializam em seu interior (MOURA, 2009, p. 25).

O processo de mobilização da infraestrutura através da perspectiva privada não se fez sem conflitos sob a gestão Lerner. Para Silva Neto (2005), a instalação dos contratos de pedágio em 26 praças em 1998 foi o elemento revelador das contradições e da incapacidade deste governo de manter os contratos, mediante a mobilização popular contra os elevados preços das tarifas praticados nas rodovias pedagiadas. Tanto que, as concessionárias acabaram conseguindo, por decisão judicial, se desobrigar da execução de obras como resposta a posição arbitrária do governador de descumprimento do contrato de concessão e corte do valor das tarifas.

A rede ferroviária também sofreu um redirecionamento efetivo no mesmo período. Em termos de novidade no campo da infraestrutura viária havia o investimento relacionado ao projeto Ferroeste desde os anos 1980, que levou à criação da estrutura que passou a compor o quadro institucional da SETR/PR, conforme já apontamos anteriormente. A Ferroeste pode

Divers@ Revista Eletrônica Interdisciplinar/Matinhos/Vol.5, n.1/p.1-92|/jan./jun.2012 
ser vista como gérmen de uma nova perspectiva de atuação direta do Estado com intuito da integração, buscando direcionar fluxos interestaduais para a rede dirigida por Curitiba, em especial para o escoamento de exportação através do porto de Paranaguá.

Conforme Vargas (2005, p. 80), a Ferroeste adveio da concessão da União, obtida em 1988, projetando as ligações de Guarapuava-Cascavel $(169 \mathrm{~km})$, ramais de Foz do Iguaçu (171 km) e Guaíra (169 km), e a ligação Guaíra-Dourados (270 km). O objetivo explícito do projeto foi aumentar a eficiência da malha ferroviária, atendendo às necessidades de conexão da região oeste e sudoeste paranaense com o Porto de Paranaguá, assim como ocorre com as regiões norte e sul do Estado. As primeiras encontravam-se subatendidas em termos de modais de escoamento da produção exportadora de soja e milho. O objetivo original de interligação se estendia para a Tríplice fronteira (Argentina e Paraguai), bem como à fronteira interestadual com Mato Grosso do Sul, visando ao atendimento dos produtores de Dourados (VARGAS, 2005).

É possível observar que as redes territoriais, longe de se transformarem em aspecto banalizado e relegado às intempéries do mercado, tornaram-se objeto de novos olhares e novos projetos. O que remonta ao velho lema que direcionou o processo de unificação territorial do Paraná conectando planejamento territorial e desenvolvimento econômico. Vários são os autores que explicitam o papel estratégico e vinculado ao poder ao qual se ligam as redes. Dias $(2009$, p.147) sintetiza a discussão afirmando que a rede é instrumento viabilizador de duas estratégias, circular e comunicar. Se para Raffestin ela permite fazer e refazer a prisão do espaço tornado território; para Lefebvre constitui meio privilegiado de produção do espaço em função dos circuitos e fluxos que são possibilitados por sua existência (DIAS, 2009, p.147). Assim, seguindo a lógica perrouxiana, o planejamento territorial no Paraná confirma que o "o espaço da economia nacional não é o território da nação, mas o domínio abrangido pelos planos econômicos dos governos e dos indivíduos" (PERROUX, 1961, p.114).

O projeto ferroviário paranaense retomado no final dos anos 1980, após décadas de predomínio do rodoviarismo, também sofreu os reveses da ótica privatista dos anos 1990 . Tanto assim que em 1997 foi concedido ao consórcio que formou a Ferrovia Paraná S/A (FERROPAR) concessão válida por 30 anos, com direito de tráfego pela rede federal também concessionada, nesse caso para a América Latina Logística (ALL). Contudo, em menos de uma década após a realização da operação de concessão foi desencadeada uma batalha

Divers@ Revista Eletrônica Interdisciplinar/Matinhos/Vol.5,n.1/p.1-92|/jan./jun.2012 
judicial que levou à retomada da Ferroeste pelo Estado do Paraná. Segundo Lima (2008), os projetos governamentais para a expansão da rede ferroviária estadual incluíam

[...] quatro ramais em estudo, um deles em direção ao porto de Paranaguá, com extensão de 306 quilômetros e investimento previsto de R\$ 1 bilhão. Atualmente, a América Latina Logística (ALL) possui uma ferrovia que liga a região central do Paraná ao porto, mas o trecho proposto pela Ferroeste deverá encurtar o caminho em 125 quilômetros. Os outros três ramais prevêem a ligação de 300 quilômetros até o município catarinense de Chapecó; mais 170 quilômetros até Foz do Iguaçu, na fronteira com o Paraguai; e 440 quilômetros até Maracaju, no Mato Grosso do Sul. O último trecho exigirá a construção de uma ponte sobre o Rio Paraná, entre Guaíra (PR) e Mundo Novo (MS).

Frustrando as expectativas dos defensores da superioridade da iniciativa privada em detrimento do setor público, o período de gestão privada das ferrovias no estado não atingiu o nível de mobilidade esperada. Tanto que a estrutura férrea continua sendo capaz de atender basicamente ao transporte de grãos, dado que a velocidade de transporte não consegue suplantar a mobilidade do modal rodoviário. Nem por isso deixa de se fazer muito expressiva no que tange ao caráter estratégico integrador do estado, e em suas projeções interestaduais e internacionais.

À guisa do que ocorreu com as áreas de investimento público, relacionados às rodovias e ferrovias, no caso do sistema portuário também se observa a ampliação do papel do setor privado. De acordo com Silva Neto (2005, p.83) foram ampliadas as concessões a operadores ${ }^{6}$ privados ao passo em que o Estado foi reduzindo sua participação em termos de investimentos na continuidade do processo de modernização do Porto de Paranaguá. Aponta o autor que a crise cambial de 1998 representou um obstáculo de grande monta para que esse processo tivesse sido levado a cabo de forma definitiva, promovendo uma redução no ritmo de avanço do setor privado sobre o setor portuário.

\section{Desafios da Integração Territorial na Última Década - novas escalas, velhos objetivos}

Observamos até aqui a relevância do processo de integração, a amplitude que as políticas públicas focadas nesse objetivo assumiram ao longo do tempo, bem como as mudanças de forma na condução das mesmas. Além disso, a partir da década de 1990 os contextos nacional e internacional terminaram por impor uma condição de debilidade

6 É importante frisar que as concessões para operação de atividades na área de porto organizado não constitui em si uma inovação deste momento. No entanto, esta assume nova dimensão e profundidade no contexto pós ano 1990.

Divers@ Revista Eletrônica Interdisciplinar/Matinhos/Vol.5,n.1/p.1-92|/jan./jun.2012 
estrutural para o Estado conduzi-las e mesmo defini-las. No entanto, não seria pertinente dizer que esse ator tenha saído de cena. Nem mesmo que teria assumido uma perspectiva de neutralidade científica, racional, tal como tende a se fazer presente no discurso mercadológico.

É fato que o fator limitante da ação pública vinculou-se à insuficiência dos mecanismos de financiamento, na medida em que o quadro de oferta de recursos internacionais tornou-o não apenas escasso, mas especialmente seletivo. Por outro lado, surgiram novos direcionamentos estratégicos para a ação do governo federal nos anos 1990, e especialmente a partir dos anos 2000. Dentre tais direcionamentos, merece destaque a estratégica integração sul-sul, a nova perspectiva regionalista, bem como a proposição geopolítica e econômica de garantir a consolidação das saídas bioceânicas. Em todos os sentidos aparecem novas questões que reposicionam velhos fatores territoriais sob novas dimensões.

A progressiva mudança brasileira de posicionamento no jogo das relações internacionais passou a guiar as ações governamentais em termos de investimento em infraestrutura. Historicamente, o Brasil havia demonstrado ser mais uma ameaça que uma parceria frente às iniciativas de fortalecimento das nações latino-americanas. Tal posição começou a ser mudada nos anos 1980, tomado o Tratado de Assunção ${ }^{7}$, em 1991, como marco da mudança de postura. Ainda assim, não é possível falar definitivamente de uma redefinição estratégica de parceiros até os anos 2000 (RIBEIRO et. al., 2009). Todavia, a nova perspectiva de atuação concedeu e vem concedendo, na medida em que está em processo, impulsionamento para o setor de transportes de forma integral.

Trata-se de um novo regionalismo na América Latina, que foi reforçado na delimitação da política internacional do governo Lula, desde o primeiro mandato. Conforme Ribeiro et. al. (2009), o adensamento da cooperação entre os países da América do Sul tornou a articulação elemento crucial no sentido de dotar de vantagens efetivas as proximidades geográficas. Para Araújo Jr (2009, p.3), a América do Sul esteve excluída do processo de ampliação das relações comerciais entre-vizinhos até o último quartel do século XX. No entanto, a principal razão para a exclusão estava no grau de fechamento da economia brasileira.

7 O Tratado de Assunção firmado entre Brasil, Argentina, Uruguai e Paraguai estabeleceu diretrizes para a criação de uma rede de livre comércio, que ficou popularmente conhecida como Mercosul.

Divers@ Revista Eletrônica Interdisciplinar/Matinhos/Vol.5,n.1/p.1-92|/jan./jun.2012 
A formação da Iniciativa para Integração da Infraestrutura Regional Sulamericana (IIRSA) em 2000, que contou com efetivo apoio do governo brasileiro representa o passo relevante no sentido da integração. Isso porque parte do pressuposto de que energia, comunicação e, sobretudo transportes representam fatores mais consistentes e relevantes para balizar a integração. Assim, aponta para a superação da retórica que a defende por meio da política de redução tarifária (ARAÚJO JR, 2009).

Ainda segundo Araújo Junior (2009), são atualmente 514 operações compondo a carteira de projetos da IIRSA, dentre os quais $60 \%$ são empreendimentos nacionais que afetam os vizinhos. O restante dos projetos relativos a investimentos em infraestrutura continental afetam em geral dois países vizinhos, tais como pontes binacionais e túneis. Há ainda aqueles que envolvem todos os países, como os relativos à difusão de serviços postais focados na facilitação de exportação para micro e pequenas empresas, e, o acordo com operadoras de telefonia celular para promoção de acordos de roaming na região (ARAÚJO JR, 2009).

A IIRSA atua com a ideia de eixos de integração territorial, para o que foram definidos 10. Dentre tais eixos, o Capricórnio (E4) é o mais relevante para a área de estudo, por abranger o estado do Paraná. O eixo abarca uma área de cerca de 2 milhões de $\mathrm{Km}^{2}$, da qual 19,57\% é área territorial brasileira. Especialmente importante fazer referência à iniciativa considerando que seu objetivo maior consiste no fortalecimento do posicionamento sulamericano na divisão internacional do trabalho. Nele estão contemplados os projetos relacionados ao Porto de Paranaguá, elemento crucial da estratégia de desenvolvimento focada na infraestrutura para exportação.

Acerca da estrutura de transportes, Ribeiro et. al. (2009) demonstra que a presença brasileira na América do Sul gera uma desproporção no quadro logístico, em função das dimensões do país. O Brasil apresenta a maior rede logística da região, sendo que $70 \%$ das estradas da América do Sul estão no território brasileiro. Todavia, a qualidade da infraestrutura rodoviária brasileira acaba sendo a maior responsável pela oferta interregional deficiente. A insuficiência torna-se ainda mais visível se tomarmos a malha ferroviária, já que a brasileira é menor que a da Argentina. O Brasil possui condição privilegiada apenas no que se refere ao sistema energético dentro do contexto da região.

Um aspecto que chama atenção no que se refere à IIRSA é a ideia de "infraestruturas sustentáveis" como elemento norteador técnico incluso na base do planejamento. A

Divers@ Revista Eletrônica Interdisciplinar/Matinhos/Vol.5,n.1/p.1-92|/jan./jun.2012 
concepção contempla, ainda que sob a pretensão técnico-científica, uma visão mais ampliada na análise dos projetos. Conforme IIRSA (2010)

[...] la Idea de "infraestructuras sostenibles" implica asociar desde La fase de planificación los proyectos de transporte, energia y comunicaciones com acciones que potencien vectores de desarollo econômico, social y ambiental, combinando infraestructura com cadenas logísticas, integración de cadenas productivas y aspectos sócio-ambientales e institucionales y SUS mecanismos de financiamento.

O financiamento dos projetos da IIRSA constitui uma evidência de que a integração representa um processo estratégico definido por e para os governos ${ }^{8}$. O que nos traz indícios contraditórios quanto à neutralidade técnica expressa nos discursos aparentemente despolitizados apresentados nos documentos da Iniciativa. Em contrapartida, o que representa sua força, a iniciativa pública dos países envolvidos, constitui também sua instabilidade. Isto porque é da característica dos investimentos em infraestrutura os resultados de longo prazo, em geral extrapolando os mandatos dos governantes. Daí a necessidade de repactuar diversas vezes a agenda de consenso.

Ao analisar a carteira de investimentos da IIRSA, observamos que o eixo Capricórnio tem previstos sete projetos no Brasil, absorvendo praticamente $10 \%$ dos recursos injetados pela iniciativa. Merece destaque o fato de que parte dos projetos pactuados na iniciativa também compõem a carteira de projetos e prioridades de investimento do Programa de Aceleração de Crescimento (PAC) do governo federal brasileiro. Na área do Capricórnio, o PAC tem provido recursos para cinco projetos. Dentre eles, dois são relativos a rodovias e pontes, dois a ferrovias e um para portos e aeroportos (ARAÚJO JUNIOR, 2009).

Fundamentalmente o eixo Capricórnio (eixo 4) integra Assunção/Paraguai a Paranaguá/Brasil. A carteira de projetos e as análises realizadas pelas equipes subsidiárias ${ }^{9}$ da IIRSA são destacáveis, na medida em que permitem vislumbrar o reforço ou enfraquecimento do sistema de circulação de mercadorias que consolidou o Porto de Paranaguá no vértice da estrutura de distribuição do estado.

Os projetos vinculados ao segmento Foz do Iguaçu-Paranaguá (destacados em no Quadro 01) reforçam a estrutura central de escoamento produtivo para exportação já

8 As instituições internacionais financiadoras dos projetos consensuados na IIRSA são: Banco Interamericano de Desenvolvimento (BID), Corporação Andina de Fomento (CAF) e o Fundo Financeiro para o Desenvolvimento da Bacia do Prata (Fonplata) (RIBEIRO et alli, 2009, p. 17).

9 Chamamos de equipes subsidiárias, as equipes técnicas de cada país responsáveis pela realização das análises de viabilidade e potencialidade dos projetos de investimentos. No caso brasileiro, técnicos especialistas do IPEA e do IPARDES participaram do GP3 - Assunção Paranaguá analisando o grau de integração das cadeias produtivas e prováveis rebatimentos dos investimentos em infraestrutura na região.

Divers@ Revista Eletrônica Interdisciplinar/Matinhos/Vol.5, n.1/p.1-92|/jan./jun.2012 
consolidado no estado do Paraná. A relevância estratégica desses investimentos é comprovada pela inclusão de parte dos mesmos tanto no Programa de Aceleração de Crescimento (PAC), como no Plano Nacional de Logística e Transporte (PNLT).

De acordo com IPEA \& IPARDES (2009, p.46), cinco projetos contemplados nos estudos da IIRSA estão vinculados à ampliação da infraestrutura do porto de Paranaguá (Quadro 01). Os projetos em questão são a construção das ferrovias Cascavel-Foz do Iguaçu e Cascavel-Guaíra; a construção da nova ferrovia Curitiba-Paranaguá; o novo trecho ferroviário Guarapuava-Curitiba; construção de nova ferrovia Ponta Grossa-Curitiba; e, a ferrovia Sudoeste - Laranjeiras do Sul a Chapecó/SC. Considera-se que tais projetos irão criar uma maior oferta de possibilidades de transporte a custos mais competitivos, o que por sua vez, tende a gerar maior demanda sobre as operações portuárias do Porto de Paranaguá. Ainda conforme essa análise existe uma boa perspectiva no que se refere ao retorno das operações graneleiras oriundas do Paraguai que passaram a utilizar a estrutura hidroviária da bacia do Paraná conduzindo parte considerável das cargas de exportação, até 2005 escoadas pelo Porto de Paranaguá, até os portos da bacia do Prata.

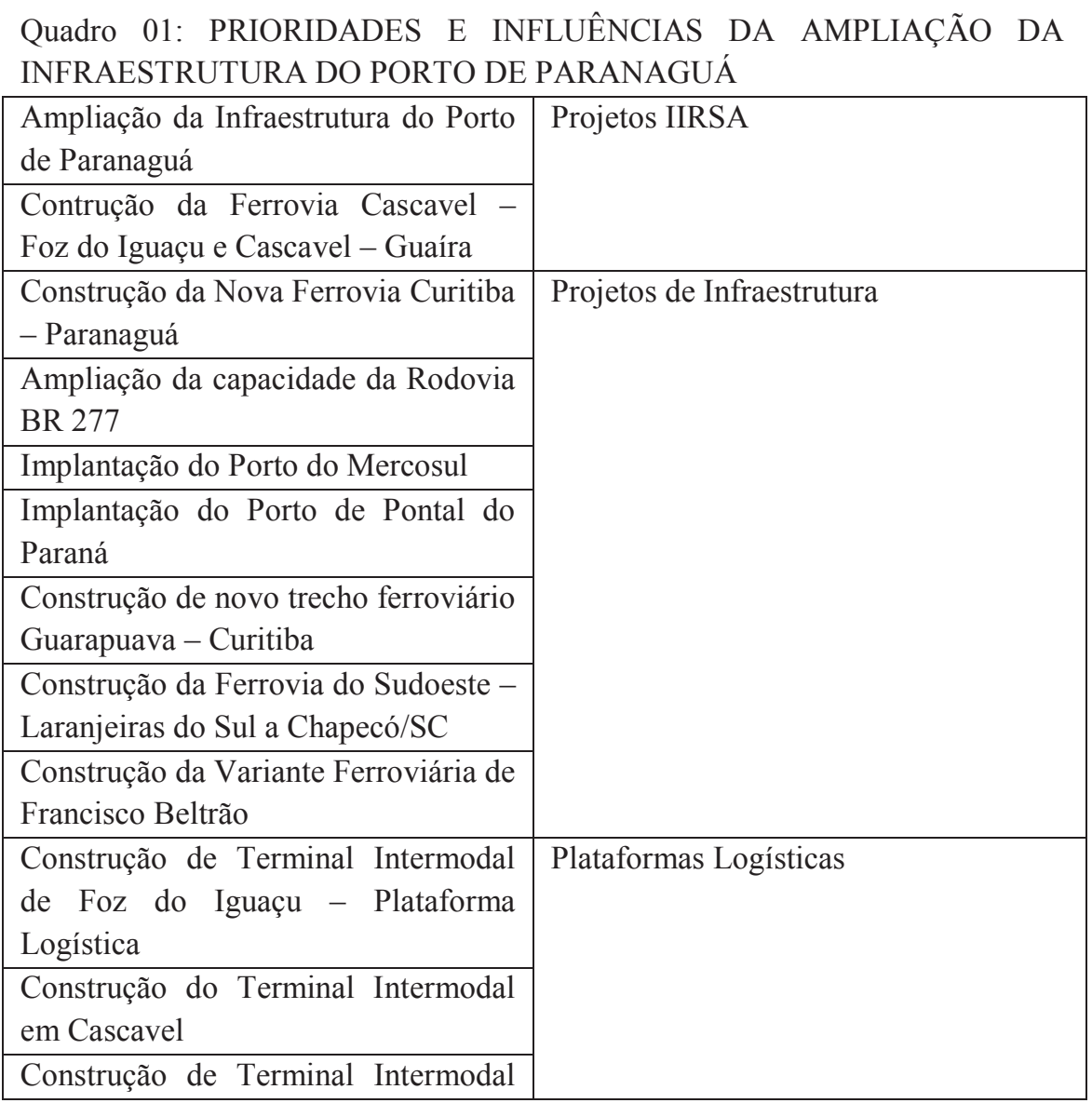

Divers@ Revista Eletrônica Interdisciplinar/Matinhos/Vol.5,n.1/p.1-92|/jan./jun.2012 


\begin{tabular}{|l|l|}
\hline de Curitiba & \\
\cline { 1 - 2 } $\begin{array}{l}\text { Construção de Terminal Intermodal } \\
\text { de Guaíra }\end{array}$ & \\
\hline Ampliação do Porto de Antonina & Projetos de Adequação \\
\hline
\end{tabular}

Fonte: IPEA/IPARDES, Projetos IIRSA, Eixo Capricórnio: Assunção Paranaguá, 2009, p. 46.

Os investimentos em pauta possibilitam aos analistas projetarem uma sobrecarga de fluxos de transporte sobre a BR277 dada a confluência da estrutura logística do estado para Curitiba, que tem nela a principal ligação com o porto de Paranaguá. Outrossim, espera-se que a potencialização do modal ferroviário proporcione maior equilíbrio no sistema de transportes do estado, tendo como consequência a redução dos custos logísticos (IPEA/IPARDES, 2009, p.47).

Os projetos vinculadas à IIRSA ainda apontam para a implantação do "Porto do Mercosul". O que implica no reordenamento e expansão dos portos do Paraná (IPEA/IPARDES, 2009). O porto de Paranaguá passa a compor um elemento do sistema portuário do estado compartilhando com o porto de Antonina e o porto de Pontal (em projeto), cada um cumprindo funções distintas. O que pode trazer uma nova perspectiva de configuração territorial impulsionada pela divisão interna do trabalho.

Ainda no sentido dos investimentos em infraestrutura que afetam ao porto de Paranaguá, é importante reiterar que o PAC tem contemplado parte significativa dos empreendimentos projetados na carteira da IIRSA, bem como alguns mais especificamente voltados para o aparelhamento portuário. Conforme Brasil (2010), dentre os investimentos previstos no PAC são diversos os que afetam diretamente o porto de Paranaguá. O primeiro deles diz respeito à construção e recuperação de berços no porto. Além disso, a construção do corredor ferroviário oeste do Paraná que permite a integração do sistema Ferroeste-ALL é estratégico na estruturação da intermodalidade. E ainda, destaca-se a adequação do contorno de Curitiba na BR116PR (BRASIL, 2010).

\section{Apontamentos Finais}

Na região analisada observa-se um processo de reafirmação da rede estruturada até os anos 1990, que concede à capital do estado, Curitiba, um papel de centralidade e à Paranaguá o papel de porto principal da economia regional. O redesenho do sistema portuário, incluindo

Divers@ Revista Eletrônica Interdisciplinar/Matinhos/Vol.5,n.1/p.1-92|/jan./jun.2012 
o porto de Antonina e de Pontal (em projeto), reforçam a estrutura portuária vinculada à rede de cidades do estado e suas vinculação regionais. No período pós-Segunda Guerra Mundial, e marcadamente a partir dos anos 1970, tal configuração econômica e socioespacial foi consolidada em função do esforço de investimento e planejamento territorial do estado do Paraná, com ênfase na infraestrutura viária.

Contemporaneamente, a integração sul-sul traz novos elementos que reforçam esses mesmos caminhos, ao mesmo tempo em que ampliam e complexificam a escala de projetos. Importa dizer que ainda não está suficientemente claro em que medida a estratégia de integração proposta através dos investimentos da IIRSA e do PAC abrirão novas perspectivas e potencializarão estruturas produtivas. No entanto, percebe-se que a prioridade efetiva continua tendo como foco as atividades econômicas voltadas para a exportação, sobretudo as commodities agrícolas que caracterizam contemporaneamente as regiões.

\section{Referências}

ARAUJO JR, José Tavares de. Infraestrutura e integração regional. Disponível em: $<$ http.www.cindesbrasil.org $>$. Acessado em setembro de 2009.

BRASIL. Ministério do Planejamento, Orçamento e Gestão. Programa de Aceleração do Crescimento - previsão de investimentos 2007-2010. Brasília: MPOG, 2010. Disponível em: $<$ http.www.brasil.gov.br/pac/investimentos>. Acessado em novembro de 2010.

COUTO, Isabel Cristina. Olhares da cidade: Curitiba e suas representações. In: Tuiuti Ciência e Cultura, n.28, FCHLA, p. 225-247, Curitiba, mar. 2002.

DIAS, Leila Christina. Redes: emergência e organização. IN: CASTRO, Iná Elias de; GOMES, Paulo César da Costa; CORREAA, Roberto Lobato (Orgs.). Geografia: Conceitos e Temas. Rio de Janeiro: Bertrand Brasil, 2009.

HARVEY, David. A produção capitalista do espaço. São Paulo: AnnaBlume, 2005.

IIRSA/Iniciativa para La integración de la infraestructura regional suramericana. Plan de Acción 2010. IN: Décimo Primera Reunión Del Comité de Dirección Ejecutiva. Buenos Aires, Argentina: IIRSA, 03 de dezembro de 2009.

Divers@ Revista Eletrônica Interdisciplinar/Matinhos/Vol.5,n.1/p.1-92|/jan./jun.2012 
IPARDES. Instituto Paranaense de Desenvolvimento. Subsídios ao Diagnóstico SócioEconômico do Paraná - Inventário da Infra-estrutura, Segunda Fase - Transporte Rodoviário, Curitiba / PR, Janeiro de 1979.

IPEA. Instituto de Pesquisa Econômica Aplicada; IPARDES. Instituto Paranaense de Desenvolvimento. Projeto IIRSA - Eixo Capricórnio GP3 - Assunção - Paranaguá. Potencial de integração produtiva e desenvolvimento de serviços logísticos de valor agregado na área de influência do GP3. Relatório Técnico, Brasília, Abril de 2009.

LIMA, Fernando Raphael Ferro de; DIAS, Agemir de Carvalho. A Infra-estrutura Rodoviária no Paraná e o Tráfego nas Rodovias Pedagiadas. In: Geografar - Revista Eletrônica do Programa de Pós-Graduação em Geografia da UFPR, Curitiba, v.3, n.1, p.16-33, Jan/jun 2008.

LIMA, Marli. Expansão da Ferroeste exigirá US\$ 3 bi. In: Valor Econômico. 12/09/2008. Disponível em: < http://www.fazenda.gov.br/resenhaeletronica/

MostraMateria.asp?cod=492388 $>$. Acessado em 02/11/2010.

MOURA, Rosa. Arranjos Urbano-regionais no Brasil: uma análise com foco em Curitiba. [Tese de Doutorado] Programa de Pós-Graduação em Geografia da Universidade Federal do Paraná, Curitiba, 2009.

PEREIRA, Luiz Carlos Bresser. A Reforma do Estado dos anos 90: Lógica e Mecanismos de Controle. In: Cadernos MARE de Reforma do Estado, Caderno 1, MARE - Ministério da Administração Federal e Reforma do Estado: Brasília-DF, 1997.

PEREIRA, Vicente de Brito. O subsetor de infra-estrutura rodoviária. In: Infra-estrutura: perspectivas de reorganização; transportes. Brasília: IPEA, 1998. v.6 t.1.

PERROUX, François. L’economie Du XXème. Paris: Presses Universitaires de France, 1961.

RIBEIRO, Daniela M. de F.; CASTELAN, Daniel R. ; LEMGRUBER, Silvia. A Política externa brasileira sul-sul na Integração Regional. In: Anais do $3^{\circ}$ Encontro Anual da ANPOCS. São Paulo, 2009.

ROCANGLIO, Cynthia. Das estradas às rodovias: meio século do rodoviarismo do Paraná. Curitiba: DER: DEAP, 1996. 120 p.

SALLUM JÚNIOR, Brasílio. Transição Política e Crise de Estado. In: SOLA, Lourdes; PAULANI, Leda M. (Orgs). Lições da década de 80. São Paulo: Edusp; Genebra:UNRISD, 1995.

Divers@ Revista Eletrônica Interdisciplinar/Matinhos/Vol.5, n.1/p.1-92|/jan./jun.2012 
SANTOS, Milton. A Natureza do Espaço - Técnica e tempo, razão e emoção. 4. Ed. 2 reimpr., São Paulo: Editora da Universidade de São Paulo, 2006.

SILVA NETO, Antônio Virgílio da. As políticas públicas de Transportes no Paraná: uma análise do governo Jaime Lerner - 1995-2002. [Dissertação de Mestrado], Programa de PósGraduação em Desenvolvimento Econômico, UFPR, Curitiba, 2005.

VARGAS, Cilos Roberto. Paraná: Desenvolvimento e Transportes. [Dissertação de Mestrado]. Mestrado em Desenvolvimento Econômico, Universidade Federal do Paraná, Curitiba, 2005. 